\title{
English Language Proficiency as a Predictor of Academic Achievement among Medical Students in Iran
}

\author{
Bahador Sadeghi \\ English Language Department, Islamic Azad University, Takestan, Iran \\ Nima Moshtaghi Kashanian \\ English Language Department, Islamic Azad University, Takestan, Iran \\ Ataollah Maleki \\ University of Medical Sciences, Zanjan, Iran
}

Aliakbar Haghdoost

Research Center for Modeling in Health, Institute for Future Studies in Health, Kerman University of Medical Sciences, Iran

\begin{abstract}
In Iran, many changes have been made in English language teaching. In academic grounds it is important to know the correlation between the expertise of students in English and their scores in different scientific subjects, before applying any further curriculum reform. The present study was designed to determine the correlation between English language proficiency and the achievement of medical students in their national comprehensive basic science exam (NCBSE). One hundred and fifty six students admitted in the academic years of 2008 and $2009(60 \%$ female and $40 \%$ male) were enrolled for the present study. The results of General English and Scientific language courses, the average marks in five consecutive semesters and the NCBSE scores were extracted from their educational files. Data was analyzed using appropriated tests such as ANOVA, Pearson's correlation and liner regression. The present data indicated that proficiency in English could significantly influence academic achievement of medical students. Furthermore, changes of policy in the students' selection or teaching styles without preparation of necessary backgrounds including increasing their English knowledge could not significantly alter the achievement of Iranian medical students.
\end{abstract}

Index Terms - English proficiency, academic achievement, correlation, national comprehensive basic science exam (NCBSE)

\section{INTRODUCTION}

English as a second or foreign language has gained much attention during the past decades in almost every country. In Iran English is taught as a foreign language in high-schools as well as in universities (Mirdehghan, HoseiniKargar, Navab, \& Mahmoodi, 2011). Aside from different language courses presented in different levels of public academic centers, there are also private institutes that teach different levels of foreign language.

As a branch of English language teaching, English for specific purposes (ESP) has gained much attention during recent years (Johns, 2013; Sarem, Hamidi, \& Mahmoudie, 2013; Zaki, 2007). Primarily ESP was divided into English for science and technology (EST), English for business and economics (EBE) and English for social sciences (ESS) by Hutchinson (1987). According to him, medical studies is a branch of English for academic purposes or a branch of EST, and students in all medical fields should learn EST as part of their academic study.

Furthermore, almost all original medical textbooks taught in universities are written in English. This should also be in mind that most communications through the Internet and scientific publications are in English too. Nevertheless, in countries such as Iran where English is not their native language, some of the scientific textbooks are or have been translated. Still English plays an important role in students' academic carriers, helping them to improve and learn at a faster pace. For the mentioned reasons, Educational Ministries in Iran made it compulsory for all students in Iranian universities to take different English courses as part of their study to improve and enhance their proficiency over their objective courses.

For the medical students under study, the English courses were presented in two different sections. The first section, called General English included 2x3 units, while in the second section students have to learn the specific language (EST) related to their objective courses. This part of their language learning was also comprised of $2 \times 3$ unites. The aim of the general English courses assigned is to teach the four general skills of reading, writing, listening and speaking, while their specific courses were administered so that students could progress further in their field of study by consulting 
through foreign websites and scanning through various articles. Throughout these courses and as a result, students should learn basic vocabulary terms and grammar helping them to understand and to act in achieving respective academic success.

Considering many improvements in the field of language teaching in recent years, students in Iran are still facing many difficulties in attaining language proficiency. Investigators in this field, discussed motivational problems concerning Iranian students in universities (Sheibani, 2012; Vaezi, 2008). They also believe that lack of proficiency among undergraduate students is due to lack of time or/and insufficient practice during high school. Classes with large number of students in universities could be another cause of bad teaching and learning among students of higher education (Sheibani, 2012; Vaezi, 2008). As a solution to such problems Noora (2008) suggested a curriculum reform, in which teacher training on new methodologies and acknowledging the English language were a great source for information. Nevertheless, for the effectiveness of such reform there should be sufficient logical evidences. To our knowledge, such study has not yet been carried out among medical students.

On the other hand, there are great deals of variables among the students admitted to medical courses, which affect their success in different exams. Students' proficiency in English is one the most important factors that influences their success both in high school as well as their university entrance exam (Dixon, 2004; Esmaeili \& Haghdoost, 2008; Graham, 1987). Another factor that is a predictor of students' achievement in different exams could be their gender and personal characteristics (Buddeberg-Fischer, Klaghofer, Abel, \& Buddeberg, 2003). Role of gender and language proficiency, in achievement of medical student in Iran, was not thoroughly studied before and needs to be considered before any curriculum reform.

Inability of some medical students in the National Comprehensive Basic Science Exam (NCBSE), or passing such exam with low grade, was noticed by the educational authorities of Iran. To increase the achievements of medical students, educational authorities tried to change the present teaching style (teacher based) to newer methods of teaching. Problem base learning (PBL) was suggested as an alternative way of teaching to increase the achievement of students in different academic subjects. In this method the topic is divided between a group of students, so that each individual has to read less from the original textbook and then to share it with other students in the group (Bayliss \& Ingram, 2006; Neville \& Britt, 2008). However, teaching according to PBL requires limited students in the classroom or requires numerous teaching academic members, in each department of universities in order to be effective. In our country due to limited teaching members in universities and overcrowded classes, it is nearly impossible to teach through PBL, similar to a suggested case by Wood (2003).

New investigations showed evidence based medicine (Gongora-Ortega, Segovia-Bernal, de Jesus Valdivia-Martinez, Galaviz-deAnda, \& Prado-Aguilar, 2012; Norman \& Shannon, 1998) and critical reading (Yudkin, 2006) are the most suitable styles of teaching for medical related students (Hadley, Hassan, \& Khan, 2008). Evidence based medicine (EBM) and related critical reading methods are now in practice in many universities in the United States (Tanenbaum, 2009), or the United Kingdom (Meats, Heneghan, Crilly, \& Glasziou, 2009) were the native language is English. To increase the gain of student in medical fields, the ministry of health and medical educations tried to change the present teaching style (teacher based) to EBM, without considering that students' accomplishment is multi-factorial and a sound knowledge of general as well as scientific English language is necessary before such reform.

Finally, before changing from teacher-based style to EBM or English language teaching style in medical universities, it is necessary to carry out many surveys surrounding the English proficiency of students and their achievements in different aspects of medical courses. The Present work was designed to see the correlation between the present circumstances of language expertise of medical students and their academic success in the exams conducted every semester and the national comprehensive basic science exam. The result of this study may help the administrative bodies to know their deficiency in the present curriculum, and take necessary steps to improve the achievement of medical students.

\section{METHOdOLOGY}

In Iran, after successful graduation in secondary schools, students are eligible in attending the university entrance exam. The Ministry of education conducts the exam, and each student can select his or her university carrier according to the score in that exam. Since medical courses have the highest demands, only competitive students with the highest marks in the university entrance exam are accepted. These students have to pass general and basic science subjects during five consecutive semesters within the medical school and achieve a prosperous score in the national comprehensive basic science exam (NCBSE) conducted by the Ministry of Health and Medical education, before beginning their clinical courses.

Kerman University of medical sciences is one of the high-grade medical universities in Iran, which has many teaching faculties such as medicine, pharmacology, dentistry, nursing, clinical laboratory courses and many other clinical related courses. Nearly one thousand students are admitted in this university every year and start their studies in different faculties.

One hundred and fifty six medical students admitted in the academic years of 2008 (51 female and 35 male) and 2009 (42 female and 28 male) were enrolled for the present study. None of the students was aware of this study, and the present data extracted from their educational files (without registering name or identification number of students), were 
provided by the head office of their department. The extracted data is the marks obtained from their English language courses that include $2 \times 3$ units of general language and $2 \times 3$ unites of scientific English. In addition to their score in the NCBSE, average marks obtained by them in five semesters before the NCBSE were also recorded.

English language dependent scientific subjects that students have to pass before attending the NCBSE are 2 units of Biochemistry, 2 units of Psychology, 2 units of Hygienic, 3 units of Anatomy and 2 units of Medical physic during the first semester. In the second semester, these subjects were four units of Biochemistry, two units of Hygienic, four units of Anatomy, and four units of Histology. Scientific subjects of the third semester include two units of Hygienic, two units of Nutrition, two units of Genetic, 4units of Physiology, 3 units of Anatomy and two units of Neuroanatomy. In the fourth semester, the medical-related courses include four units of Microbiology, five units of Physiology, 3 units of Immunology and one unit of Virology. Finally, during the fifth semester students have to pass five units of Pathology, four units of Parasitology, and one unit of Embryology.

\section{RESUlTS AND ANALYSIS}

To analysis the data, students were primarily divided to four groups according to their gender and their year of admittance. Described statistic according to the demographic variables (gender and the admittance year) of students and their score in English language courses and averages of marks obtained during five semesters and their NCBSE scores were checked first. To determine differences between four groups, one-way analysis of variance (ANOVA) with Tukey's post-hoc test was executed. Then, the correlation of scores in different English courses and NCBSE were assessed by Pearson correlation coefficient. Finally, we modeled the score of students in NCBSE exam based on the gender, the admittance year, and scores of students in different English courses by linear regression method. We used SPSS (version 19, IBM Company, USA) for our analysis and p-value less than 0.05 was considered as significant.

Analyzed data showed $59.3 \%$ of students admitted in the year 2008 were female, whereas this figure for the students of 2009 was $60 \%$. Described statistics of four groups of students are presented in the table 1. Analyzed data showed distributions of score were normal in all the language subjects (minimum 10 and maximum 20), as well as average marks scored in different semester.

ANOVA analysis of different marks obtained showed while a non-significant difference exists between scores obtained for the general language 1(15.30-16.33), female students of $2008(18.26 \pm 1.63)$ significantly $(\mathrm{p}<0.01)$ scored higher marks in the general language 2 than both groups of students (female $=16.85 \pm 2.68$, male $=16.35 \pm 2.38)$ of 2009 . They $(18.70 \pm 2.16)$ also significantly scored $(\mathrm{p}<0.01)$ higher marks in the scientific language 2 than corresponding groups of students (female $=17.30 \pm 1.97$, male $=16.47 \pm 2.74$ ) admitted in the year of 2009. Furthermore, except average marks of the first semester, male students of 2009 significantly scored lower marks $(\mathrm{p}<0.05-0.01)$ than other students of 2008 or female students admitted in the year of 2009 (figure 1). Finally, male students of 2009 scored lower marks $(118.89 \pm 11.48)$ in the NCBSE exam than other three groups, as shown in table 1.

Due to the limited number of students in different groups, we carried out two-tailed bivariate Pearson's correlations, irrespective of gender or year of admittance for all the students. These data indicated beside a significant $(\mathrm{R}=0.40-0.64$, $\mathrm{P}<0.001)$ correlation between different language courses, both general English and scientific language courses have highly significant $(\mathrm{R}=0.29-0.70, \mathrm{P}<0.01)$ correlation with different scores obtained in five semesters or the NCBSE. Summary of these correlations are present in table 2. In addition, determined correlation between the average of different English language scores and the NCBSE of all the participants showed a highly significant $(\mathrm{R}=0.50, \mathrm{P}<0.001)$ correlation. Figure 2 is a summary of this correlation.

In univariate regression model, we found that sources of students in both general and scientific English courses had significant association with their scours in NCBSE. However, in multivariate analysis, only the regression coefficient of 1.76 of general language 2 was significant $(\mathrm{P}<0.01)$. In crude analysis, the coefficient for gender was -3.72 , but the adjusted coefficient dropped to -0.96 , however both coefficients were not statistically significant.

\section{DisCUSSIONS AND CONCLUSIONS}

Calculated descriptive results indicated that all students scored high marks for the appropriated language courses during four consecutive semesters as presented in table 1. On the other hand, the average of marks obtained for each semester was in intermediate range (passing mark is 10 and the highest mark is 20), while they scored lower marks (passing mark 95 and the highest mark 200) in the NCBSE. Furthermore, a quick look to table 2 points out highly significant correlation $(\mathrm{R}=0.59-0.64, \mathrm{P}<0.001)$ between the language courses presented in each four consecutive semesters and the average of marks obtained in that term. However, the correlation between language courses and the average of marks obtained in the fifth semester or the NCBSE reduced $(\mathrm{R}=0.29-0.48, \mathrm{P}<0.01)$. Comparable results reported by Maleki and his colleagues (Maleki \& Zangani, 2007) showed significant correlation between English language proficiency and achievement in English speaking and writing subjects. Equivalent results also reported by Komba and colleagues (Komba, Kafanabo, Njabili, \& Kira, 2012) in Tanzania showed positive correlation between students' academic performance and their abilities in written English language skills.

Here, our data for the first time may point out that while students prepare for the appropriated language exam, they score higher marks in other scientific subjects. However, they fail to keep in mind the general or scientific English 
language during the fifth semester or the NCBSE. This could be the cause of reduction in their performances in those exams. In addition, the present data clearly indicates that the magnificence of knowledge in general and scientific English is essential for a non English-speaking community in the achievement of their medical subjects throughout their academic study.

Proficiency over scientific English language among higher education is not only the problem of Iranian students. In many none English speaking such as Malaysia (Gobel, Thang, Sidhu, Oon, \& Chan, 2013), Pakistan (Fikree \& Marsh, 1996), Tanzania (Komba et al., 2012), Spain (Abella \& Urrutia, 2013) and even in English speaking countries like Australia (Mann, Canny, Reser, \& Rajan, 2013), the United Kingdom (Meats et al., 2009) and the USA (Tanenbaum, 2009), it was shown that students ability in scientific English (reading, writing and speaking) directly increases the success of medical students. That is why in most of these countries including Iran, educational authorities try to change classical teaching methods to suggested new methods in order to increase students' achievement.

As mentioned before, PBL was suggested as an alternative way of teaching to increase the achievement of students in different academic subjects. However, teaching according to PBL requires limited students in the classroom or requires numerous teaching academic members, in each department of such universities in order to be effective. Furthermore, proficiency in general as well as scientific English language is one of the necessities for the implication of PBL. In our country due to limited teaching members in most universities and overcrowded classes, it is nearly impossible to teach through the PBL method.

EBM (Gongora-Ortega et al., 2012; Norman \& Shannon, 1998) and critical reading (Yudkin, 2006) were two other suggested methods of teaching for the medical related students (Hadley et al., 2008). Critical reading is the process of constantly interacting with the text while reading it, understanding more and deeper from what is just written. Though EBM and related critical reading are now in practice in many universities in the United States (Tanenbaum, 2009), or the United Kingdom (Meats et al., 2009) were the native language is English, its implantation in Iran is not suitable, due to lack of inadequate knowledge of English. Unfortunately, to increase the gain of students in medical fields, the ministry of health and medical educations in Iran tried to change the present teaching style (teacher based) to evidence based medicine, without thoroughly considering students control over English. Expertise in the English language scales is a necessity for such system as suggested by many investigators (Ahmadian \& Hosseini, 2012; Al-Hattab, 2006; AlSawalha \& Chow, 2012; Haghdoost et al., 2010; Mann et al., 2013), and results of the present study (table 2) clearly indicated lack of such expertise among our medical students.

Our data (figure 1) also indicated that male students admitted in year 2009 scored lower marks through their five semesters or their NCBSE compared to corresponding female students, while that was not the case for the student accepted in 2008. According to previous reports, (Fikree \& Marsh, 1996; Shekhar \& Devi, 2012) in the Asian communities it was shown female students dynamically study better than male students. This statement may be true for the ratio of students admitted to the medical universities every year, as shown in table 1 . Nearly $60 \%$ of the students admitted in the two academic years of 2008 and 2009 were female; however only one group of our students showed such difference and the male students admitted in 2008 had equivalent score as their female counterparts. The only explanation for this difference could be the policy change of the authorities. In the year 2008, students were accepted in the medical school, according to their score in the university entrance exam, while in the year 2009 acceptance of students were according to the university entrance exam as well as ethnicity.

Dobel and colleagues (Gobel et al., 2013) showed students from urban places score better than their rural counterparts in different language courses. Our present data may confirm their hypothesis as well as conclusions of Fikree and March (Fikree \& Marsh, 1996) or Shekhar and Devi (Shekhar \& Devi, 2012). Because both groups of students admitted in the year 2008, score equal marks in their language courses and different semesters or their NCBSE, but only male students in the second group had lower marks in their scientific languages and likewise in the average marks obtained in different semesters and the NCBSE.

Finally, results of determined prediction effects (liner regression model) of students' English language score, gender, and year of admittance on the NCBSE score are shown in table 4. These results showed the highest predictor of success in the NCBSE are through knowledge of general as well as scientific language courses. The findings also indicate that the gender or the year of admittance had lower significant impact.

In conclusion, the present data indicated language proficiency in general as well as scientific use could significantly influence academic achievement of medical students. Furthermore, changes of policy in the students' selection or teaching styles without preparation of necessary backgrounds, such as having sound knowledge over the English language (reading, writing, as well as speaking), could not affect the achievement of Iranian medical students.

APPEndiX. TABLES AND Figures 
TABLE 1:

DESCRIBED STATISTIC OF DIFFERENT MARKS OBTAINED B Y MEDICAL STUDENTS (N=156) ADMITTED IN ACADEMIC YEARS OF 2008 AND 2009 IN KERMAN UNIVERSITY OF MEDICAL SCIENCES.

\begin{tabular}{|l|l|l|l|l|}
\hline Admittance year & $\mathbf{2 0 0 8}$ & $\mathbf{2 0 0 9}$ \\
\hline Subjects & Female $(\mathbf{n}=\mathbf{5 1})$ & Male $(\mathbf{n}=\mathbf{3 5})$ & Female $(\mathbf{n = 4 2})$ & Male $(\mathbf{n = 2 8})$ \\
\hline General language 1 & $15.59(3.29)$ & $15.30(3.61)$ & $16.55(1.85)$ & $16.33(2.01)$ \\
General language 2 & $18.26(1.63)$ & $17.16(2.23)$ & $16.85(2.68)$ & $16.35(2.38)$ \\
Scientific language 1 & $17.98(2.42)$ & $17.57(2.31)$ & $18.19(1.64)$ & $16.80(2.37)^{*}$ \\
Scientific language 2 & $18.70(2.16)$ & $18.14(2.22)$ & $17.30(1.97)$ & $16.47(2.74)^{*}$ \\
Average mark of semester 1 & $15.95(1.66)$ & $15.65(1.52)$ & $16.19(1.30)$ & $15.39(0.92)^{*}$ \\
Average mark of semester 2 & $15.25(1.96)$ & $14.61(2.02)$ & $14.98(1.48)$ & $13.99(1.27)^{*}$ \\
Average mark of semester 3 & $15.80(1.70)$ & $15.77(1.58)$ & $15.47(1.44)$ & $14.41(1.27)^{*}$ \\
Average mark of semester 4 & $15.28(1.42)$ & $15.24(1.34)$ & $15.37(1.43)$ & $13.88(0.98)^{*}$ \\
Average mark of semester 5 & $15.64(1.50)$ & $15.62(1.36)$ & $15.77(1.67)$ & $14.36(1.22)^{*}$ \\
National Basic Science Score & $124.90(17.35)$ & $124.00(14.12)$ & $126.64(13.97)$ & $118.89(11.48)^{*}$ \\
\hline
\end{tabular}

Figures presented are calculated mean and the ones in the brackets are standard deviations of their respectful mean. The * marks show significant $(\mathrm{P}<0.05-0.01)$ differences between male and female students admitted in academic year of 2009, while mark presented significant $(\mathrm{P}<0.01)$ difference between female students of 2008 and all the students of 2009.

TABLE 2:

TWO TAILED BIVARIATE PEARSON'S CORRELATION DETERMINED FOR ALL THE MEDICAL STUDENTS (N=156), ADMITTED DURING ACADEMIC YEARS OF 2008 AND 2009 IN KERMAN UNIVERSITY OF MEDICAL SCIENCES.

\begin{tabular}{|l|l|l|l|l|}
\hline Subjects & $\begin{array}{l}\text { General } \\
\text { language 1 }\end{array}$ & $\begin{array}{l}\text { General } \\
\text { language 2 }\end{array}$ & $\begin{array}{l}\text { Scientific } \\
\text { language 1 }\end{array}$ & $\begin{array}{l}\text { Scientific } \\
\text { language 2 }\end{array}$ \\
\hline Average mark of semester 1 & $0.64^{*}$ & $0.49^{*}$ & $0.49^{*}$ & $0.50^{*}$ \\
Average mark of semester 2 & $0.54^{*}$ & $0.64^{*}$ & $0.52^{*}$ & $0.60^{*}$ \\
Average mark of semester 3 & $0.42^{*}$ & $0.62^{*}$ & $0.59^{*}$ & $0.70^{*}$ \\
Average mark of semester 4 & $0.41^{*}$ & $0.58^{*}$ & $0.49^{*}$ & $0.59^{*}$ \\
Average mark of semester 5 & $0.29^{*}$ & $0.48^{*}$ & $0.39^{*}$ & $0.48^{*}$ \\
National Basic Science Score & $0.38^{*}$ & $0.45^{*}$ & $0.39^{*}$ & $0.37^{*}$ \\
\hline
\end{tabular}

Figures presented are the calculated correlation factor $(\boldsymbol{R})$ between respective rows and columns. The * marks indicate highly significant $(\mathrm{p}<0.01)$ correlations between different language courses and scores obtained in particular exams.

TABLE 3:

PREDICTION EFFECT OF STUDENTS' ENGLISH LANGUAGE SCORE, GENDER, AND YEAR OF ADMITTANCE ON THE NATIONAL BASIC SCIENCE SCORE, DETERMINED BY A LINER REGRESSION MODEL.

\begin{tabular}{|l|l|l|l|l|}
\cline { 2 - 5 } \multicolumn{1}{c|}{} & \multicolumn{3}{l|}{ Crude Analysis } & Adjusted analysis \\
\hline Variables & Regression coefficient & P value & Regression coefficient & Predicted value \\
\hline General language 1 & 1.94 & $<0.001$ & 0.80 & 0.11 \\
\hline General language 2 & 3.0 & $<0.001$ & 1.76 & 0.01 \\
\hline Scientific language 1 & 2.62 & $<0.001$ & 0.71 & 0.30 \\
\hline Scientific language 2 & 2.42 & $<0.001$ & 0.58 & 0.39 \\
\hline Gender differences & -3.72 & 0.13 & -0.96 & 0.67 \\
\hline Year of admittance & -0.88 & 0.72 & 0.79 & 0.75 \\
\hline
\end{tabular}

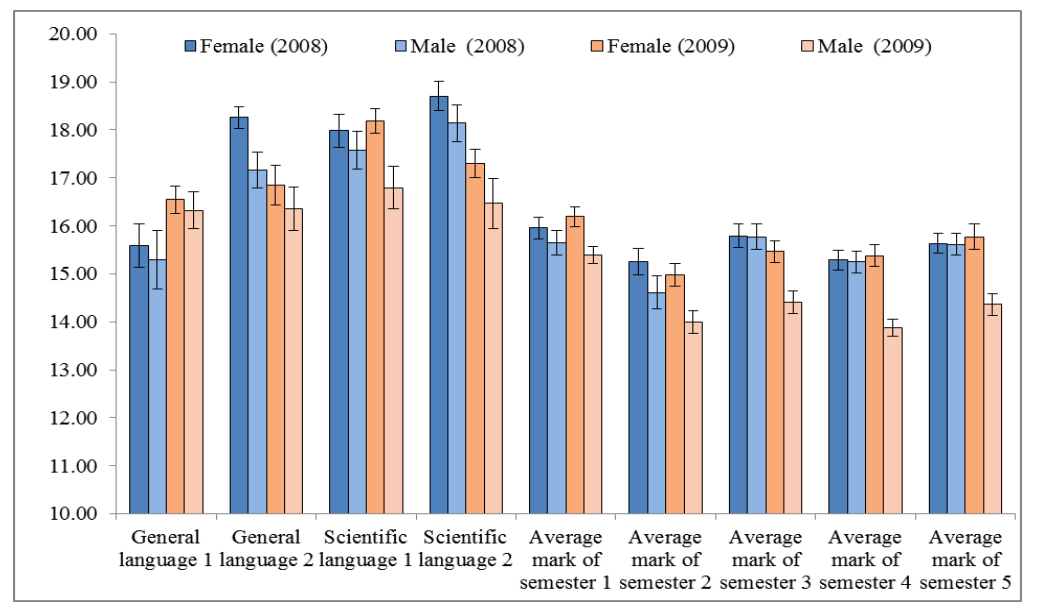

Figure 1: Comparison of different scores obtained by the medical students $(\mathrm{n}=156)$. Analyzed data showed while gender did not affect the score among students admitted in the academic year of 2008 , gender significantly influenced $(\mathrm{p}<0.05-0.001)$ the marks obtained by the students admitted in the academic year of 2009 . 


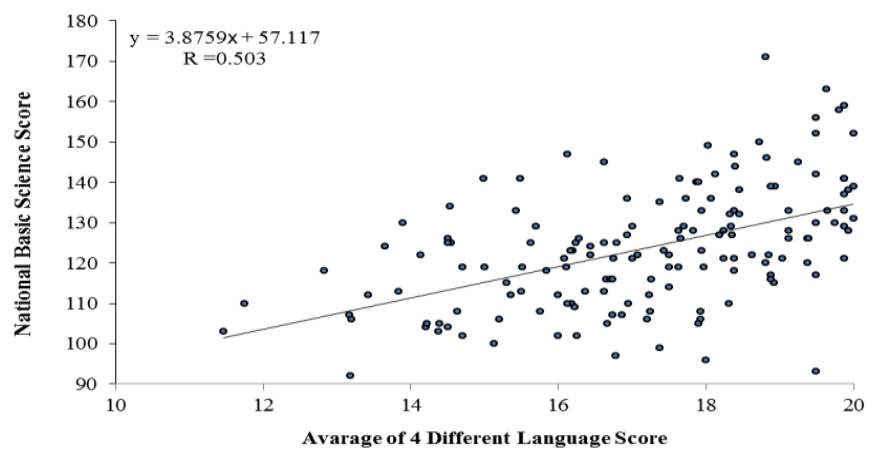

Figure 2: Correlation of National basic science score against average of marks obtained in four different language courses (general English language 1 and 2, and scientific English language course 1 and 2). Each one of the language courses was 3 units. Regression coefficient (R=0.503) is highly significant $(\mathrm{P}<0.001)$.

\section{REFERENCES}

[1] Abella, R., \& Urrutia, J. (2013). An examination of the validity of English language achievement test scores in a LEP student population. 7-12. http://www.digitalcommons.fiu.edu.

[2] Ahmadian, M., \& Hosseini, S. (2012). A Study of the Relationship between Iranian EFL Learners' Multiple Intelligences and Their Performance on Writing. Mediterranean Journal of Social Sciences, 3(1), 111-126.

[3] Al-Hattab, A. (2006). Self-esteem and Writing Achievement of Saudi EFL Students in Secondary Schools. (Master Degree in Methods of Teaching English as a Foreign Language), Taibah University. Saudi Arabia.

[4] Al-Sawalha, A. M. S., \& Chow, T. V. F. (2012). The effects of proficiency on the writing process of jordanian efl university students. Academic Research, 3(2), 379-388.

[5] Bayliss, A., \& Ingram, D. (2006). IELTS as a predictor of academic language performance. Paper presented at the Australian International Education Conference.

[6] Buddeberg-Fischer, B., Klaghofer, R., Abel, T., \& Buddeberg, C. (2003). The influence of gender and personality traits on the career planning of Swiss medical students. Swiss Medical Weekly, 133(39-40), 535-540.

[7] Dixon, D. (2004). Relation between variables of preadmission, medical school performance, and COMLEX-USA levels 1 and 2 performance. J Am Osteopath Assoc, 104(8), 332-336.

[8] Esmaeili, A., \& Haghdoost, A. A. (2008). The internal consistency of medical students' scores in their physiopathology and clinical courses. Indian J Med Sci, 62(7), 267-274.

[9] Fikree, F. F., \& Marsh, D. R. (1996). Critical appraisal by reading for medical students--a case study from Pakistan. J Pak Med Assoc, 46(4), 80-83.

[10] Gobel, P., Thang, S. M., Sidhu, G. K., Oon, S. I., \& Chan, Y. F. (2013). Attributions to Success and Failure in English Language Learning: A Comparative Study of Urban and Rural Undergraduates in Malaysia. Asian Social Science, 9(2), 53-62.

[11] Gongora-Ortega, J., Segovia-Bernal, Y., Valdivia-Martinez Jde, J., Galaviz-DeAnda, J. M., \& Prado-Aguilar, C. A. (2012). Educational interventions to improve the effectiveness in clinical competence of general practitioners: problem-based versus critical reading-based learning. BMC Med Educ, 12(1), 53-65.

[12] Graham, J. G. (1987). English language proficiency and the prediction of academic success. TESOL Quarterly, 21(3), 505-521.

[13] Hadley, J., Hassan, I., \& Khan, K. S. (2008). Knowledge and beliefs concerning evidence-based practice amongst complementary and alternative medicine health care practitioners and allied health care professionals: A questionnaire survey. BMC complementary and alternative medicine, 8(1), 45-52.

[14] Haghdoost, A.-A., Sadeghirad, B., Shamsaddini, A., Nafisi, Y., Dehghani, M. R., \& Ayatollahi Musavi, S. A. (2010). Academic Achievement and its Indicators Among Students Awarded Scholarship in Medical Fields Hakim Research Journal, 13(1), $1-10$.

[15] Hutchinson, T. a. W., Alan. (1987). English for Specific Purposes A learning-centered approach: Cambridge University Press.

[16] Johns, A. (2013). The history of English for specific purposes research. The handbook of English for specific purposes. Boston: Wiley-Blackwell.

[17] Komba, S. C., Kafanabo, E. J., Njabili, A. F., \& Kira, E. S. (2012). Comparison between students' academic performance and their abilities in written English language skills: A Tanzanian perspective. International Journal of Development and Sustainability, 2(1), 305-325.

[18] Maleki, A., \& Zangani, E. (2007). A survey on the relationship between English language proficiency and the academic achievement of Iranian EFL students. Asian EFL Journal, 9(1), 86-96.

[19] Mann, C., Canny, B. J., Reser, D. H., \& Rajan, R. (2013). Poorer verbal working memory for a second language selectively impacts academic achievement in university medical students. PeerJ, 1(22), 1-26. doi: 10.7717/peerj.22

[20] Meats, E., Heneghan, C., Crilly, M., \& Glasziou, P. (2009). Evidence-based medicine teaching in UK medical schools. Med Teach, 31(4), 332-337.

[21] Mirdehghan, M., HoseiniKargar, N., Navab, S., \& Mahmoodi, T. (2011). Cultural barriers: pros and cons on ELT in Iran. International Journal of English Linguistics, 1(1), 15-20.

[22] Neville, D. O., \& Britt, D. W. (2008). A Problem - Based Learning Approach to Integrating Foreign Language Into Engineering. Foreign Language Annals, 40(2), 226-246.

[23] Noora, A. (2008). Iranian Undergraduates Non-English Majors' Language Learning Preferences. GEMA Online Journal of Language Studies, 18(2), 33-44. 
[24] Norman, G. R., \& Shannon, S. I. (1998). Effectiveness of instruction in critical appraisal (evidence-based medicine) skills: a critical appraisal. Canadian Medical Association Journal, 158(2), 177-181.

[25] Sarem, S. N., Hamidi, H., \& Mahmoudie, R. (2013). A critical look at textbook evaluation: a case study of evaluating an ESP course-book: English for international tourism. International Research Journal of Applied and Basic Sciences, 4(2), 372-380.

[26] Sheibani, O.-b. (2012). Language Learning Motivation among Iranian Undergraduate Students. World Applied Sciences Journal, 19(6), 838-846.

[27] Shekhar, C., \& Devi, R. (2012). Achievement Motivation across Gender and Different Academic Majors. Journal of Educational and Developmental Psychology, 2(2), 105-109.

[28] Tanenbaum, S. J. (2009). Comparative effectiveness research: evidence-based medicine meets health care reform in the USA. $J$ Eval Clin Pract, 15(6), 976-984.

[29] Vaezi, Z. (2008). Language learning motivation among Iranian undergraduate students. World Applied Sciences Journal, 5(1), 54-61.

[30] Wood, D. F. (2003). ABC of learning and teaching in medicine: Problem based learning. BMJ: British Medical Journal, 326(7384), 328-330.

[31] Yudkin, B. (2006). Critical reading: making sense of papers in life sciences and medicine: Routledge.

[32] Zaki, S. (2007). English for specific purposes: implications in medical education. J Coll Physicians Surg Pak, 17(1), 1-2.

Bahador Sadeghi, an assistant professor of Applied Linguistics holds a doctorate degree in TEFL from the University of Isfahan, Iran. He also holds three MAs in TEFL, English Translation and International Relations from Tehran Islamic Azad University, Isfahan University and Allameh Tabatabai University respectively. He has been lecturing different subjects in TEFL, Translation studies, General English and ESP at several universities in Iran for the last twenty two years. He has both published and presented a number of articles in some international journals and conferences. He is also a certified translator to the judiciary power in Iran and he has been, as a simultaneous interpreter, actively involved in many national and international seminars, sport events and tourism projects.

Nima Moshtaghi Kashanian born in Kerman, Iran on September $16^{\text {th }} 1985$. B.A in English Literature, Bahonar University, Kerman, Iran 2003-2008. M.A in English Teaching, Islamic Azad University of Takestan, Iran in 2013. Teached English as a Foreign language in many institutes for more than 1000 hours. Currently teaching in Jahad Daneshgahi, Tehran branch in Karaj, Iran. Interested in studying Epidemiology and applied linguistics.

Ataollah Maleki, Professor of TEFL at Zanjan Medical Sciences University, Iran. His main interest of research is communication strategies, EFL teaching, teaching and testing, ESP, discourse analysis, and phonetics. He has been engaged in teaching English and applied linguistics for more than twenty years. He holds a Ph. D degree in TEFL, an MA in TEFL, and a postgraduate diploma in applied linguistics and phonetics. He has published a number of books and articles in his areas of interest in academic journals.

AliAkbar Haghdoost, born in Kerman, Iran on September first 1971. Among many academic achievements are Doctorate in Medicine, Iran University of Medical Sciences, Tehran, Iran, 1990-1997, Doctor of Philosophy in Epidemiology and bio-statistics, London School of Hygiene and Tropical Medicine, Faculty of Medicine, London University, 2000-2004, Diploma of Epidemiology and bio-statistics, London School of Hygiene and Tropical Medicine, 2004.

He was Head of the research institute of the "Future studies in health", Kerman University of Medical Sciences in 2012, The head of Hygiene school, Kerman university of medical sciences in 2011-2012 and Member of scientific committee, the national scientific Olympiad for students in medical fields, Shiraz, Iran in 2010. His recent published works are, Modeling of Human Immunodeficiency Virus Modes of Transmission in Iran, Zero new HIV infections, Zero discrimination, and Zero AIDS-related deaths: Feasible goals or ambitious visions on the occasion of the world AIDS Day? And Effect of extremely low frequency electromagnetic field exposure on sleep quality in high voltage substations. His research interests are regarding statistics, workshops, web based training courses and more.

Prof. Haghdoost was an advisory of WHO office in Iran on baseline assessment of malaria situation in high risk areas; a project supported by global fund in 2009, a Member of national (Iranian) medical education scientific board in 2008-2009 and many other positions throughout his academic career. He has achieved many awards; among his first awards are Distinct young researcher among Iranian medical students, 1995, Outstanding student in mathematics field in secondary schools in Kerman province, 1987, and Distinct student among medical students in Iran University of Medical Sciences, 1997. 